Article

\title{
Comparison of Cone Beam Computed Tomography and Digital Radiography in Detecting Separated Endodontic Files and Strip Perforation
}

\author{
Mehrdad Abdinian ${ }^{1}$, Saba Moshkforoush ${ }^{2}$, Hamidreza Hemati ${ }^{3}$, Parisa Soltani ${ }^{1, *}$, \\ Mansoure Moshkforoushan ${ }^{4}$ and Gianrico Spagnuolo ${ }^{5, *}$ (D) \\ 1 Department of Oral and Maxillofacial Radiology, Dental Implants Research Center, Dental Research Institute, \\ School of Dentistry, Isfahan University of Medical Sciences, Isfahan 81746, Iran; abdinian@dnt.mui.ac.ir \\ 2 Dental Students' Research Committee, School of Dentistry, Isfahan University of Medical Sciences, \\ Isfahan 81746, Iran; saba_msh74@yahoo.com \\ 3 Department of Endodontics, School of Dentistry, Isfahan University of Medical Sciences, Isfahan 81746, Iran; \\ hr.hemati94@gmail.com \\ 4 Dentist, Private Practice, Isfahan 81746, Iran; mansouremoshkforoushan@yahoo.com \\ 5 Department of Neurosciences, Reproductive and Odontostomatological Sciences, University of Naples \\ "Federico II", 80131 Naples, Italy \\ * Correspondence: p.soltani@dnt.mui.ac.ir (P.S.); gspagnuo@unina.it (G.S.)
}

Received: 8 November 2020; Accepted: 2 December 2020; Published: 5 December 2020

check for updates

Featured Application: Based on our findings, cone beam computed tomography was superior for diagnosing strip perforation of filled root canals, while digital periapical radiographs performed better in the detection of separated rotary files. The selection of appropriate imaging modalities for the diagnosis of endodontic complications must be performed on an individual basis according to the initial radiographic and clinical signs and symptoms.

\begin{abstract}
The separation of endodontic files and strip perforation are among procedural intraoperative complications which may ultimately lead to the failure of root canal treatment. The aim of the present study was to compare the diagnostic potential of cone beam computed tomography (CBCT) and digital periapical radiographs in detecting separated rotary files and strip perforation in filled canals. Fifty human mandibular molars were selected for this study. The teeth were randomly divided into two groups based on endodontic errors (i.e., file separation and strip perforation). In each group, 25 of 50 mesial canals were randomly chosen for simulating the errors, while the other 25 canals were considered as the control group. In group one, a simulation of the separation of rotary files was performed using ProTaper F2 files. Strip perforation of the root canals in group two was achieved by number 2 and 3 Gates Glidden drills in the coronal third of the root canals. Digital periapical radiographs in two different horizontal angles and high-resolution CBCT scans were obtained from the teeth mounted on a dry human mandible with simulated soft tissue covering. Three experienced observers who were unaware of the study groups evaluated the digital periapical and CBCT image sets in two separate readings. Intraobserver and interobserver agreements, as well as accuracy, sensitivity, specificity, positive predictive value (PPV), and negative predictive value (NPV), were calculated and compared. Intraobserver and interobserver agreements ranged from poor to excellent and poor to good, respectively. The accuracy, sensitivity, specificity, PPV, and NPV for digital radiography in detecting separated files were $0.950,0.813,0.957,0.929$, and 0.880 , respectively. The same values for CBCT were $0.747,0.667,0.900,0.833$, and 0.783 , respectively. For the diagnosis of strip perforation, these values were $0.855,0.800,0.909,0.889$, and 0.833 for periapical radiography and $0.955,1.000$, $0.920,0.926$, and 1.000 for CBCT. In conclusion, CBCT was superior for diagnosing strip perforation of the filled root canals, while digital periapical radiographs performed better in the detection of separated rotary files.
\end{abstract}


Keywords: endodontics; root canal therapy; cone beam computed tomography; dental digital radiography

\section{Introduction}

Inflammation of the dental pulp can occur as a result of severe caries, periodontal diseases, or traumatic events. Root canal therapy and other adjunct treatment options aim to remove the inflamed tissues or suppress their inflammatory response based on the stage and reversibility of inflammation [1-3]. A successful endodontic treatment needs thorough debridement and complete sealing of the root canal system. Failure in endodontic treatment manifests itself by clinical signs and symptoms or on radiographic examinations. A myriad of factors can lead to the failure of root canal treatment, which can be classified as preoperative, intraoperative, or postoperative factors $[4,5]$. Separation of endodontic files and strip perforation are among the procedural intraoperative errors which ultimately may lead to the failure of root canal treatment $[6,7]$. The possibility of separation of rotary nickel-titanium (NiTi) files is shown to range from $0.4 \%$ to $4.4 \%$ [8]. Several etiologic factors such as operator proficiency, root canal anatomy, torque, reuse of NiTi files, autoclaving cycles, and materials used in combination with the rotary files are among the factors leading to the separation of endodontic files [9-11]. In addition, mesial roots of the mandibular molars are susceptible to strip perforations due to their thin dentinal walls [12].

Radiographic examinations play an important role in diagnosing the etiology of endodontic failures and procedural errors [13,14]. Several imaging modalities can be used for evaluating the outcome of root canal treatments. Digital periapical radiographs are readily available, as they have a low radiation dose and are easy to obtain [15]. However, they are limited by their two-dimensional projection. Cone beam computed tomography $(\mathrm{CBCT})$, as the most commonly used three-dimensional imaging modality in dentistry, is widely used for endodontic purposes [16-18]. The presence of metallic artifacts and a higher radiation dose are some of the issues which need to be considered when CBCT is being planned to evaluate the root canal system before, during, and after root canal treatments [19]. Therefore, imaging modalities for monitoring the outcome of endodontic treatments must be selected based on a cost-benefit approach.

Limited studies have compared the accuracy of periapical radiography and CBCT in detecting separated rotary files in root canals. Additionally, some studies have reported a better performance of periapical radiography in detecting strip perforations, while others concluded that perforations can be detected more accurately on CBCT images. Accordingly, the comparison of digital periapical radiography and $\mathrm{CBCT}$ for detecting separated rotary instruments and strip perforation in filled canals would be valuable for clinical diagnosis and decision-making from a cost-benefit approach. Therefore, the aim of the present study was to compare the diagnostic potential of CBCT and digital periapical radiographs in detecting separated rotary files and strip perforation in filled canals.

\section{Materials and Methods}

This study was approved by the Ethics Committee of Isfahan University of Medical Sciences (number IR.MUI.RESEARCH.REC.1398.710).

\subsection{Sample Preparation}

Fifty human mandibular molars, extracted due to periodontal problems, were collected and stored in purified filtered water at room temperature. The teeth were subjected to radiographic examination and teeth with previous endodontic treatment, external and internal root resorption, root caries, anomalies, cracks, fractures, unmatured apices, calcified root canals, and mesial roots with more than two root canals were excluded from the study. 
The access cavity was prepared on the teeth and the canal patency was obtained by \#10 k file (Mani Inc, Utsunomiya, Tochigi, Japan). In order to measure the working length, a \#10 k file was inserted into the root canal until its tip was visible from the apex. The length of the file was assessed and the real working length determined to be $1 \mathrm{~mm}$ shorter than the calculated file length. Mesial canals were chosen for simulating endodontic errors due to the higher incidence of errors in these canals as compared to the distal canals. The mesial root canals were prepared by the crown down technique using the gold ProTaper rotary system (Dentsply Maillefer, Ballaigues, Switzerland) by endo motor (Eighteeth, Changzhou Sifary Technology Co, Changzhou, China) and $1 \mathrm{~mL}$ of $2.5 \%$ sodium hypochlorite as irrigant between instruments. The teeth were then randomly divided into two groups based on endodontic errors, that is, file separation and strip perforation. In each group, 25 of 50 canals were randomly chosen for simulating the errors, while the other 25 canals were considered as the control group without simulation of the endodontic errors.

In group one (file separation group), in order to break the file into the canal, a fracture point was created $2 \mathrm{~mm}$ from the tip of the gold ProTaper F2 rotary file. The file was inserted in the prepared canal and twisted till it was broken at the end of canal. The rest of the canal was obturated by the lateral condensation technique using an AH 26 sealer (Dentsply Maillefer, Ballaigues, Switzerland) and gutta percha points (Meta Biomed, Cheongju-si, Korea).

In group two (strip perforation group), number 2 and 3 Gates Glidden drills (Mani Inc., Tochigi, Japan) were used in the coronal third of the canal to create strip perforation in the danger zone. The perforation area was confirmed by the insertion of a \#20 k file and the canal was obturated by lateral condensation technique. The control canals were prepared using the ProTaper rotary system and were obturated by gutta percha points and the AH 26 sealer.

The teeth were mounted in the previously prepared sockets of molar teeth in a dry mandible. The mandible was covered by $0.5 \mathrm{~cm}$ red wax (Polywax, Izmir, Turkey) as soft tissue equivalent.

\subsection{Imaging Procedure}

Digital periapical radiographs were acquired in two different horizontal angles (perpendicularly and 20 degrees distally) using a size 2 photostimulable phosphor plate (PSP, Durr Dental, Bietigheim-Bissingen, Germany) and the exposure parameters of $8 \mathrm{~mA}, 63 \mathrm{kVp}$, and $0.160 \mathrm{~s}$ by an intraoral radiographic unit (Planmeca, Helsinki, Finland). A film holder (Kerr, Orange, CA, USA) was used to place the detector parallel to the long axis of the teeth.

For obtaining the CBCT scans, the dry mandible was placed on the chin rest of the scanner. A VGi evo CBCT scanner (NewTom, Verona, Italy) was used with the following protocol: $5 \mathrm{~cm} \times 10 \mathrm{~cm}$ field of view, HiRes mode, $110 \mathrm{kVp}, 3 \mathrm{~mA}, 1.8 \mathrm{~s}$ emission (pulsed), and $0.1 \mathrm{~mm}$ voxel size.

\subsection{Image Evaluation}

Three observers (two oral and maxillofacial radiologists and one endodontist) with four to eleven years of experience analyzed digital radiographs and CBCT images in a dimly lit room without any time restriction affecting the quality of their judgment. The observers were unaware of the study groups. Images were displayed on a 20" MSI all-in-one MS-AA8A monitor (MSI, New Taipei, Taiwan) with $1600 \times 900$ pixels resolution. The calibration procedure was performed by demonstration and discussion on five radiographs not related to the current study. Digital radiographs were exported from the Scanora software (Soredex, Tuusula, Finland) and saved in Joint Photographic Experts Group (JPEG) format to be randomly displayed for each observer. СВCT images were analyzed using the dedicated NNT software (NewTom, Verona, Italy). The observers could scroll in axial, sagittal, and coronal planes. In addition, they had the ability to use cross-sectional images in every desired plane. The observers were also allowed to change the magnification, brightness, contrast, and sharpness of all the image sets if needed (Figures 1 and 2) An observer's judgement was recorded by a 5-point scale as follows: (1) definitely present; (2) probably present; (3) uncertain/unable to tell; (4) probably absent; and (5) 
definitely absent. In order to obtain intraobserver agreement, $20 \%$ of the images were evaluated again after ten days by all of the observers.

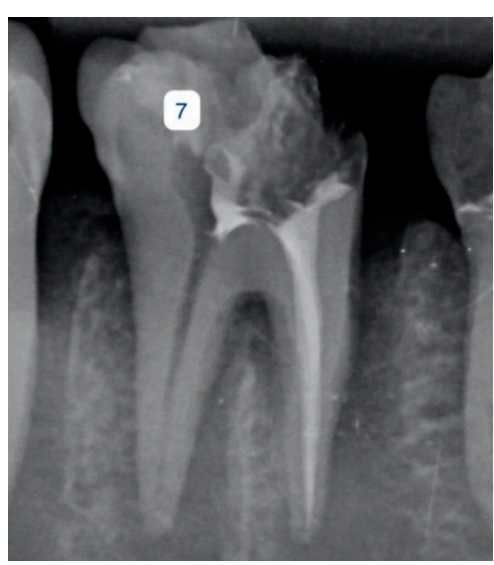

(a)

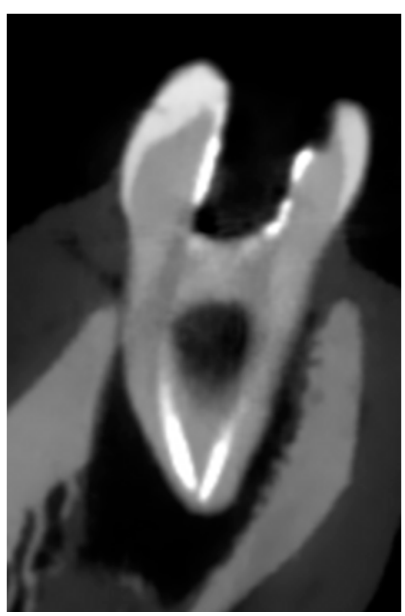

(c)

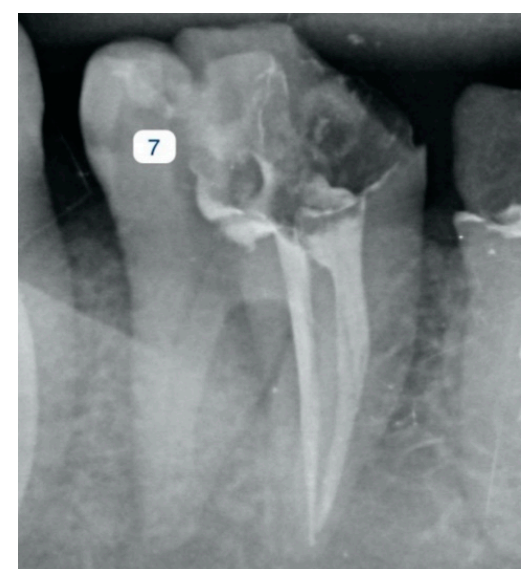

(b)

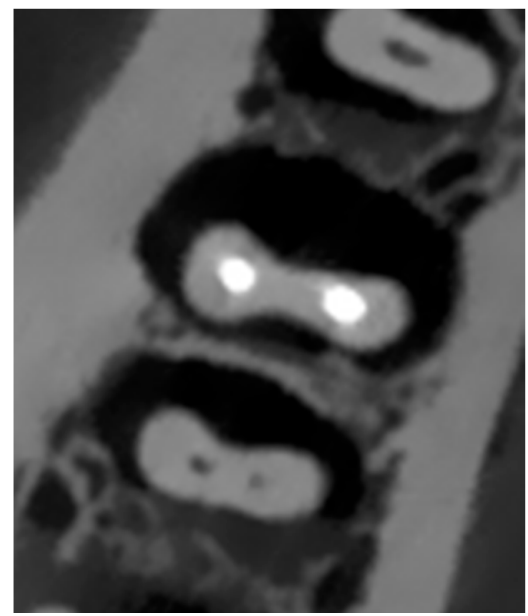

(d)

Figure 1. Digital periapical radiographs with (a) perpendicular and (b) distal horizontal angles and cone beam computed tomography (CBCT) images in (c) coronal and (d) axial views of a tooth with a separated file in the mesiolingual root canal.

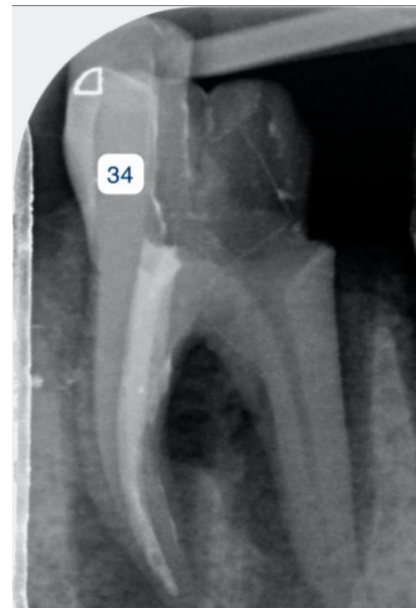

(a)

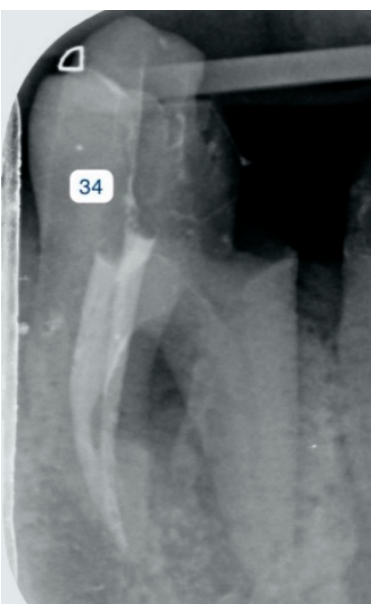

(b)

Figure 2. Cont. 


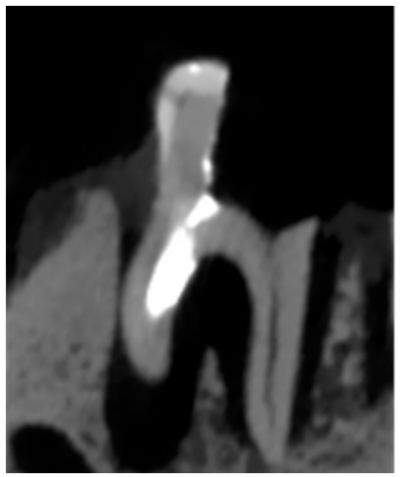

(c)

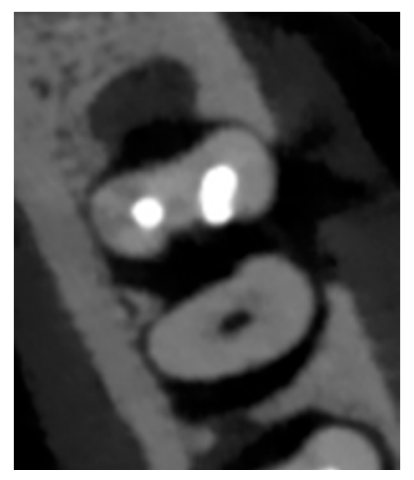

(d)

Figure 2. Digital periapical radiographs with (a) perpendicular and (b) distal horizontal angles and CBCT images in (c) sagittal and (d) axial views of a tooth with strip perforation of the mesiobuccal root canal.

\subsection{Statistical Analysis}

Statistical analysis was performed using Statistical Package for the Social Sciences (SPSS, v 24, IBM, Armonk, NY, USA). An intraclass correlation coefficient (ICC) was used to compute inter- and intraobserver agreement. It has been suggested that ICC values less than 0.5 are indicative of poor reliability, values between 0.5 and 0.75 indicate moderate reliability, values between 0.75 and 0.9 indicate good reliability, and values greater than 0.90 indicate excellent reliability [20]. In order to assess the diagnostic accuracy of imaging modalities, the area under the receiver operating characteristic curves and $95 \%$ confidence intervals were calculated. Sensitivity, specificity, positive predictive value (PPV), and negative predictive value (NPV) were also calculated. For each imaging technique, identifying the endodontic complication equated to score 1 and 2, and not identifying the endodontic failure equated to score 4 and 5 . Cases with score 3 were not considered in the analysis. The level of significance was set at $\alpha=0.05$.

\section{Results}

\subsection{Intraobserver and Interobserver Agreement}

For all imaging modalities and groups of complications, ICC values of intraobserver agreement were from moderate (0.713) to good (0.814) for observer 1 , from moderate (0.706) to excellent $(1.000)$ for observer 2, and from poor (0.252) to excellent (0.980) for observer 3.

Interobserver agreement calculated by ICC was moderate $(0.615-0.652)$ for the three observers in viewing digital periapical radiographic image sets, from poor (0.197) to good (0.785) for the three observers in viewing CBCT image sets, and from poor $(0.356)$ to moderate $(0.622)$ for the three observers in evaluating all image sets (digital periapical radiographs and $\mathrm{CBCT}$ ) for the first reading. These results were statistically significant $(p<0.05)$. In addition, for the second reading the ICC value ranged from poor (0.409) to moderate (0.566).

\subsection{Accuracy, Specificity, Sensitivity, NPV, and PPV}

In detecting separated files (group 1), diagnostic accuracy for the observers ranged from 0.750 to 0.896 for digital periapical images and from 0.576 to 0.773 for CBCT images. Moreover, the accuracy values calculated based on the observers' average for the detection of separated files was 0.950 for digital periapical radiography and 0.747 for CBCT (Table 1). In general, for detecting separated files, accuracy, sensitivity, specificity, PPV, and NPV were higher in digital periapical radiographs than in CBCT. 
Table 1. Accuracy, sensitivity, specificity, positive predictive value (PPV), and negative predictive value (NPV) values for each observer and observer's average in detecting separated endodontic files (group 1).

\begin{tabular}{|c|c|c|c|c|c|c|c|c|c|}
\hline & & \multirow{2}{*}{ Accuracy } & \multirow{2}{*}{$p$} & \multicolumn{2}{|c|}{$\begin{array}{l}\text { 95\% Confidence } \\
\text { Interval }\end{array}$} & \multirow{2}{*}{ Sensitivity } & \multirow{2}{*}{ Specificity } & \multirow{2}{*}{ PPV } & \multirow{2}{*}{ NPV } \\
\hline & & & & $\begin{array}{l}\text { Lower } \\
\text { Bound }\end{array}$ & $\begin{array}{l}\text { Upper } \\
\text { Bound }\end{array}$ & & & & \\
\hline \multirow[t]{2}{*}{ Observer 1} & $\begin{array}{l}\text { Periapical } \\
\text { radiograph }\end{array}$ & 0.750 & 0.003 & 0.607 & 0.893 & 0.560 & 0.920 & 0.875 & 0.677 \\
\hline & $\mathrm{CBCT}$ & 0.576 & 0.369 & 0.412 & 0.739 & 0.440 & 0.760 & 0.647 & 0.576 \\
\hline \multirow[t]{2}{*}{ Observer 2} & $\begin{array}{l}\text { Periapical } \\
\text { radiograph }\end{array}$ & 0.875 & 0.000 & 0.766 & 0.984 & 0.840 & 0.920 & 0.913 & 0.852 \\
\hline & СВCT & 0.773 & 0.001 & 0.635 & 0.911 & 0.826 & 0.720 & 0.731 & 0.818 \\
\hline \multirow[t]{2}{*}{ Observer 3} & $\begin{array}{l}\text { Periapical } \\
\text { radiograph }\end{array}$ & 0.896 & 0.000 & 0.795 & 0.997 & 0.958 & 0.833 & 0.852 & 0.952 \\
\hline & $\mathrm{CBCT}$ & 0.659 & 0.059 & 0.502 & 0.817 & 0.440 & 0.840 & 0.733 & 0.600 \\
\hline \multirow{2}{*}{$\begin{array}{l}\text { Observers' } \\
\text { average }\end{array}$} & $\begin{array}{l}\text { Periapical } \\
\text { radiograph }\end{array}$ & 0.950 & 0.000 & 0.839 & 1.000 & 0.813 & 0.957 & 0.929 & 0.880 \\
\hline & CBCT & 0.747 & 0.031 & 0.541 & 0.954 & 0.667 & 0.900 & 0.833 & 0.783 \\
\hline
\end{tabular}

In detecting strip perforation (group 2), the diagnostic accuracy for the observers ranged from 0.727 to 0.932 for digital periapical images and from 0.900 to 0.960 for CBCT images. Moreover, the accuracy values calculated based on the observers' averages for detection of strip perforation were 0.855 for digital periapical radiography and 0.955 for CBCT (Table 2). On average, for detecting strip perforation, accuracy, sensitivity, specificity, PPV, and NPV were higher in CBCT than in digital periapical radiographs.

Table 2. Accuracy, sensitivity, specificity, PPV, and NPV values for each observer and observers' average in detecting strip perforation (group 2).

\begin{tabular}{|c|c|c|c|c|c|c|c|c|c|}
\hline & & \multirow{2}{*}{ Accuracy } & \multirow{2}{*}{$p$} & \multicolumn{2}{|c|}{$\begin{array}{l}\text { 95\% Confidence } \\
\text { Interval }\end{array}$} & \multirow{2}{*}{ Sensitivity } & \multirow{2}{*}{ Specificity } & \multirow{2}{*}{ PPV } & \multirow{2}{*}{ NPV } \\
\hline & & & & $\begin{array}{l}\text { Lower } \\
\text { Bound }\end{array}$ & $\begin{array}{l}\text { Upper } \\
\text { Bound }\end{array}$ & & & & \\
\hline \multirow{2}{*}{ Observer 1} & $\begin{array}{l}\text { Periapical } \\
\text { radiograph }\end{array}$ & 0.795 & 0.001 & 0.656 & 0.935 & 0.640 & 0.920 & 0.889 & 0.719 \\
\hline & СВCТ & 0.920 & 0.000 & 0.832 & 1.000 & 1.000 & 0.840 & 0.862 & 1.000 \\
\hline \multirow[t]{2}{*}{ Observer 2} & $\begin{array}{l}\text { Periapical } \\
\text { radiograph }\end{array}$ & 0.932 & 0.000 & 0.845 & 1.000 & 0.957 & 0.913 & 0.917 & 0.955 \\
\hline & СВCТ & 0.900 & 0.000 & 0.803 & 0.997 & 0.960 & 0.840 & 0.857 & 0.955 \\
\hline \multirow[t]{2}{*}{ Observer 3} & $\begin{array}{l}\text { Periapical } \\
\text { radiograph }\end{array}$ & 0.727 & 0.010 & 0.574 & 0.881 & 0.750 & 0.625 & 0.667 & 0.714 \\
\hline & $\mathrm{CBCT}$ & 0.960 & 0.000 & 0.897 & 1.000 & 1.000 & 0.920 & 0.926 & 1.000 \\
\hline \multirow{2}{*}{$\begin{array}{l}\text { Observers' } \\
\text { average }\end{array}$} & $\begin{array}{l}\text { Periapical } \\
\text { radiograph }\end{array}$ & 0.855 & 0.000 & 0.729 & 0.980 & 0.800 & 0.909 & 0.889 & 0.833 \\
\hline & СBCT & 0.955 & 0.000 & 0.883 & 1.000 & 1.000 & 0.920 & 0.926 & 1.000 \\
\hline
\end{tabular}

\section{Discussion}

The findings of the present study suggest that the diagnostic accuracy of digital periapical radiography is higher than that for $\mathrm{CBCT}$ for detecting separated endodontic files, while they suggest that $\mathrm{CBCT}$ has a higher accuracy for detecting strip perforation of root canals. 
Several studies have compared the diagnostic potential of CBCT and digital periapical radiography for detecting endodontic complications. In the study performed by Ayatollahi et al., the diagnostic abilities of CBCT and periapical radiography for detecting separated \#10 and \#35 hand files were tested. Similar to our findings, their results indicated that the sensitivity, specificity, PPV, NPV, and diagnostic accuracy of digital periapical radiography was better than CBCT in both sizes of separated instruments [21]. D'addazio et al. simulated a series of endodontic complications in extracted teeth and compared the accuracy of CBCT and periapical radiography. Based on their findings, periapical radiographs were more accurate for the detection of file fragments compared with $\mathrm{CBCT}$, although the observed difference was not significant [22]. Their findings are consistent with our results. In another study, Rosen et al. used both hand and rotary separated files. Similar to our results, they indicated that periapical radiographs were superior to CBCT imaging in the detection of separated instruments [23]. Additionally, Romos-Brito et al. simulated the separation of reciprocating NiTi files, rotary NiTi files, and stainless steel files. Their results showed that in the absence of filling, accuracy values were high for periapical radiographs of different digital systems and CBCT images with different voxel sizes. In filled root canals, however, the accuracy of periapical radiographs was significantly higher than that of CBCT images [24]. High-density filling material can create additional artifacts and thus may compromise the diagnosis of small fragments of separated endodontic instruments. A few other studies have used rotary instruments to simulate file separation. Consistent with our findings, Koç et al. in their study concluded that digital radiography performs better for detecting separated rotary instruments [25]. Moreover, in the study of Alemam et al., conventional and digital periapical radiographs and $\mathrm{CBCT}$ performed equally for the detection of separated rotary endodontic files. In obturated canals, the accuracy and sensitivity of CBCT were significantly lower, which can be a result of the presence of additional artifacts of the filling materials [17].

In the study of D'addazio et al., all root perforation defects were identified with CBCT, while periapical radiographs were unable to identify the majority of perforations [22]. Haghanifar et al. performed a study to compare the diagnostic characteristics of CBCT and digital periapical radiography in three angles for detecting root perforation in obturated and non-obturated root canals. Their study showed higher sensitivity, specificity, PPV, and NPV for CBCT in non-obturated root canals, while in obturated root canals all of these factors were higher for periapical radiography. Thus, the insertion of radiopaque filling materials led to a decrease in the diagnostic capabilities of $\mathrm{CBCT}$ imaging in their study [26]. However, in our findings, CBCT was superior to periapical radiography in filled canals. The difference between the findings can be attributed to the smaller voxel size of the CBCT unit used in our study. In addition, observers in the current study were able to view the cross-sectional images in any desired plane, which may enhance the diagnostic potential of CBCT by incorporating its unprecedented three-dimensional capabilities. Shemesh et al. in their study concluded that the risk of misdiagnosis of strip perforation is high with both periapical radiography and CBCT imaging, However, CBCT is significantly more sensitive in the diagnosis of strip perforation [27].

It is important to select appropriate imaging techniques for diagnosing endodontic errors and complications. When complications are suspected in clinical examination and initial periapical radiography, several points need to be considered before choosing further radiographic examinations. $\mathrm{CBCT}$ is the imaging modality with the highest radiation dose for dental purposes, and exposes the patients to relatively higher radiation doses as compared to periapical radiography [28]. The effective dose of a CBCT scan with a small field of view is approximately $50 \mu \mathrm{Sv}$, while two digital periapical radiographs obtained by PSP and using rectangular collimation have an effective dose of about $2.5 \mu \mathrm{Sv}$ [29]. Moreover, for endodontic purposes, СBCT scans with limited field of view and small voxel sizes are preferred to enhance the diagnostic potential [30]. Additionally, in CBCT, the presence of metallic objects in the field of view might lead to beam-hardening artifacts which may in turn affect the detection of fine details [31]. On the other hand, conventional radiographs are two-dimensional and may present a distorted view of the imaged structures [32]. Our findings suggest that while CBCT is more beneficial for the diagnosis of strip perforation, for the detection of separated endodontic 
instruments, obtaining another periapical radiograph with a different horizontal angulation might be preferable to CBCT scanning.

In the joint position statement developed by the American Association of Endodontists and American Academy of Oral and Maxillofacial Radiology, CBCT with limited field of view was recommended as the modality of choice for treatment complications such as separated endodontic instruments [33]. However, in our in vitro study, digital periapical radiography was superior to CBCT for the detection of separated rotary files. Similar findings were also observed in the other studies discussed above. One reason for the difficulty in the correct detection of endodontic instruments in СBCT images is the presence of artifacts. Artifacts are defined as systematic discrepancy between CBCT gray values and actual attenuation coefficients [34]. Artifacts occur as a result of several etiologic factors. For instance, area detectors in $\mathrm{CBCT}$ detect scatter radiation from the entire imaging field. Moreover, high-density materials create additional artifacts by hardening X-ray beams [35]. Gutta percha, endodontic instruments, and root canal sealers are materials with high density which may participate in the production of beam-hardening artifacts [36-38]. Scanning parameters such as exposure settings, voxel size, СBCT device, and field of view alter the magnitude of these artifacts $[35,39]$. Blooming is another imaging artifact which may lead to overestimation of the object size in CBCT images. This artifact is a result of several factors, such as beam hardening and low spatial resolution [40]. For instance, implants placed in the jaw bones of frozen human cadaver heads showed an average blooming of $12-15 \%$ in their size [41]. Blooming can alter the shape and size of the separated instruments in CBCT images, making detection more challenging. These artifacts are not present in the periapical radiography, and thus they do not compromise the accuracy of detecting separated instruments in periapical radiographs. In addition, the low contrast resolution of $\mathrm{CBCT}$, which is a result of area detectors collecting scattered radiation, can compromise differentiating file fragments from gutta percha material in the filled root canals [17].

The three-dimensional nature of СВCТ imaging, however, helps in the detection of several endodontic complications. For instance, as our findings show, the strip perforation of root canals can be better detected using different $\mathrm{CBCT}$ image views. Axial views can show the extrusion of endodontic filling materials from the danger zone of roots. This view cannot be obtained by periapical radiography. In addition, using cross-sectional views in different planes, the root canal can be viewed with smaller thicknesses, whereas periapical radiography as a conventional imaging technique provides the ray-sum of the entire thickness of tooth, supporting bone, and soft tissues.

One of the limitations of this study is its in vitro design, which relies on the simulation of clinical scenarios that may not be accurate. In addition, the poor interobserver agreement observed in the detection of separated files in СВCT images reflects the low diagnostic potential of CBCT images for detecting file fragments. It is worth noting that this study used specific types of endodontic instruments (i.e., ProTaper F2 rotary files) for the simulation of instrument separation. The results may vary for instruments with different sizes or materials. Additionally, strip perforations were made in the coronal third of the canal. Simulating perfortions in different regions of the root canal may lead to different findings.

\section{Conclusions}

The findings of the present study indicate that cone beam computed tomography was superior for diagnosing strip perforation of filled root canals, while digital periapical radiographs performed better in detecting separated rotary files. The selection of appropriate imaging modalities for the diagnosis of endodontic complications must be performed on an individual basis according to the initial radiographic and clinical signs and symptoms, with special attention to the principles for radiologic examinations: that the patient's exposure be as low as reasonably achievable and as low as diagnostically acceptable. 
Author Contributions: M.A. and H.H. conceived and designed the experiment; M.A., S.M., P.S., H.H. and M.M. performed the experiments; P.S. and S.M. analyzed the data; M.A., S.M., G.S. interpreted the findings; P.S. and S.M. wrote the paper; M.A., H.H., M.M., and G.S. critically revised the draft All authors have read and agreed to the published version of the manuscript.

Funding: This research study was funded by Isfahan University of Medical Sciences (\#398915).

Acknowledgments: The authors would like to thank Maryam Shafiei for her scientific contribution in the study.

Conflicts of Interest: The authors declare no conflict of interest.

\section{References}

1. Spagnuolo, G.; Codispoti, B.; Marrelli, M.; Rengo, C.; Rengo, S.; Tatullo, M. Commitment of oral-derived stem cells in dental and maxillofacial applications. Dent. J. 2018, 6, 72. [CrossRef] [PubMed]

2. De Figueiredo, F.E.D.; Lima, L.F.; Oliveira, L.S.; Ribeiro, M.A.; Correa, M.B.; Brito-Junior, M.; Faria-e-Silva, A.L. Effectiveness of a reciprocating single file, single cone endodontic treatment approach: A randomized controlled pragmatic clinical trial. Clin. Oral. Investig. 2019, 24, 1-11. [CrossRef] [PubMed]

3. Nosrat, A.; Kolahdouzan, A.; Khatibi, A.H.; Verma, P.; Jamshidi, D.; Nevins, A.J.; Torabinejad, M. Clinical, radiographic, and histologic outcome of regenerative endodontic treatment in human teeth using a novel collagen-hydroxyapatite scaffold. J. Endod. 2019, 45, 136-143. [CrossRef]

4. Iqbal, A. The factors responsible for endodontic treatment failure in the permanent dentitions of the patients reported to the college of dentistry, the University of Aljouf, Kingdom of Saudi Arabia. J. Clin. Diagn. Res. 2016, 10, 146. [CrossRef] [PubMed]

5. Yamaguchi, M.; Noiri, Y.; Itoh, Y.; Komichi, S.; Yagi, K.; Uemura, R.; Naruse, H.; Matsui, S.; Kuriki, N.; Hayashi, M.; et al. Factors that cause endodontic failures in general practices in Japan. BMC Oral. Health 2018, 18, 70. [CrossRef]

6. Akbar, I. Radiographic study of the problems and failures of endodontic treatment. Int. J. Health Sci. 2015, 9, 111. [CrossRef]

7. Tabassum, S.; Khan, F.R. Failure of endodontic treatment: The usual suspects. Eur. J. Dent. 2016, $10,144$. [CrossRef]

8. Saber, S.E.-D.M. Factors influencing the fracture of rotary nickel titanium instruments. Endod. Pract. Today 2008, 2, 273-283.

9. Ametrano, G.; D’Antò, V.; Di Caprio, M.; Simeone, M.; Rengo, S.; Spagnuolo, G. Effects of sodium hypochlorite and ethylenediaminetetraacetic acid on rotary nickel-titanium instruments evaluated using atomic force microscopy. Int. Endod. J. 2011, 44, 203-209. [CrossRef]

10. Madarati, A.; Watts, D.; Qualtrough, A. Factors contributing to the separation of endodontic files. Br. Dent. J. 2008, 204, 241-245. [CrossRef]

11. Spagnuolo, G.; Ametrano, G.; D’Antò, V.; Rengo, C.; Simeone, M.; Riccitiello, F.; Amato, M. Effect of autoclaving on the surfaces of TiN-coated and conventional nickel-titanium rotary instruments. Int. Endod. J. 2012, 45, 1148-1155. [CrossRef] [PubMed]

12. Eghbal, M.J.; Fazlyab, M.; Asgary, S. Repair of a strip perforation with calcium-enriched mixture cement: A case report. Iran Endod. J. 2014, 9, 225-228. [PubMed]

13. Çalışkan, M.K.; Kaval, M.E.; Tekin, U.; Ünal, T. Radiographic and histological evaluation of persistent periapical lesions associated with endodontic failures after apical microsurgery. Int. Endod. J. 2016, 49, 1011-1019. [CrossRef] [PubMed]

14. Nicoloso, G.F.; Pötter, I.G.; Rocha, R.d.O.; Montagner, F.; Casagrande, L. A comparative evaluation of endodontic treatments for immature necrotic permanent teeth based on clinical and radiographic outcomes: A systematic review and meta-analysis. Int. J. Paediatr. Dent. 2017, 27, 217-227. [CrossRef]

15. Mehdizadeh, M.; Booshehri, S.G.; Kazemzadeh, F.; Soltani, P.; Motamedi, M.R. Level of knowledge of dental practitioners in Isfahan, Iran about cone-beam computed tomography and digital radiography. Imaging Sci. Dent. 2015, 45, 133-135. [CrossRef]

16. Hasheminia, S.M.; Farhad, A.; Sheikhi, M.; Soltani, P.; Hendi, S.S.; Ahmadi, M. Cone-beam computed tomographic analysis of canal transportation and centering ability of single-file systems. J. Endod. 2018, 44, 1788-1791. [CrossRef] 
17. Alemam, S.; Abuelsadat, S.; Saber, S.; Elsewify, T. Accuracy, sensitivity and specificity of three imaging modalities in detection of separated intracanal instruments. G. Ital. Endod. 2020, 34. [CrossRef]

18. Patel, S.; Brown, J.; Semper, M.; Abella, F.; Mannocci, F. European society of endodontology position statement: Use of cone beam computed tomography in Endodontics: European Society of Endodontology (ESE) developed by. Int. Endod. J. 2019, 52, 1675-1678. [CrossRef]

19. Krug, R.; Connert, T.; Beinicke, A.; Soliman, S.; Schubert, A.; Kiefner, P.; Sonntag, D.; Weiger, R.; Krastl, G. When and how do endodontic specialists use cone-beam computed tomography? Aust. Endod. J. 2019, 45, 365-372. [CrossRef]

20. Koo, T.K.; Li, M.Y. A guideline of selecting and reporting intraclass correlation coefficients for reliability research. J. Chiropr. Med. 2016, 15, 155-163. [CrossRef]

21. Ayatollahi, F.; Tabrizizadeh, M.; Razavi, H.; Mowji, M. Diagnostic value of cone-beam computed tomography and digital periapical radiography in detection of separated instruments. Iran Endod. J. 2019, 14, 14-17.

22. D'Addazio, P.; Campos, C.; Özcan, M.; Teixeira, H.; Passoni, R.; Carvalho, A. A comparative study between cone-beam computed tomography and periapical radiographs in the diagnosis of simulated endodontic complications. Int. Endod. J. 2011, 44, 218-224. [CrossRef] [PubMed]

23. Rosen, E.; Venezia, N.B.; Azizi, H.; Kamburoglu, K.; Meirowitz, A.; Ziv-Baran, T.; Tsesis, I. A comparison of cone-beam computed tomography with periapical radiography in the detection of separated instruments retained in the apical third of root canal-filled teeth. J. Endod. 2016, 42, 1035-1039. [CrossRef] [PubMed]

24. Brito, A.C.R.; Verner, F.S.; Junqueira, R.B.; Yamasaki, M.C.; Queiroz, P.M.; Freitas, D.Q.; de Oliveira-Santos, C. Detection of fractured endodontic instruments in root canals: Comparison between different digital radiography systems and cone-beam computed tomography. J. Endod. 2017, 43, 544-549. [CrossRef]

25. Koç, C.; Sönmez, G.; Yılmaz, F.; Karahan, S.; Kamburoğlu, K. Comparison of the accuracy of periapical radiography with CBCT taken at 3 different voxel sizes in detecting simulated endodontic complications: An ex vivo study. Dentomaxillofac. Radiol. 2018, 47, 20170399. [CrossRef] [PubMed]

26. Haghanifar, S.; Moudi, E.; Mesgarani, A.; Bijani, A.; Abbaszadeh, N. A comparative study of cone-beam computed tomography and digital periapical radiography in detecting mandibular molars root perforations. Imaging Sci. Dent. 2014, 44, 115-119. [CrossRef]

27. Shemesh, H.; Cristescu, R.C.; Wesselink, P.R.; Wu, M.-K. The use of cone-beam computed tomography and digital periapical radiographs to diagnose root perforations. J. Endod. 2011, 37, 513-516. [CrossRef]

28. Nikeghbal, K.; Zamanian, Z.; Shahidi, S.; Spagnuolo, G.; Soltani, P. Designing and fabricating nano-structured and micro-structured radiation shields for protection against CBCT exposure. Materials 2020, $13,4371$. [CrossRef]

29. Mallya, S.; Lam, E. White and Pharoah's Oral Radiology E-Book: Principles and Interpretation; Elsevier: Gurgaon, India, 2019.

30. Kohli, M.R.; Schloss, T. The use of Cone Beam Computer Tomography (CBCT) in endodontics. Curr. Oral Health Rep. 2019, 6, 377-384. [CrossRef]

31. Codari, M.; Vasconcelos, K.d.F.; Nicolielo, L.F.P.; Neto, F.H.; Jacobs, R. Quantitative evaluation of metal artifacts using different CBCT devices, high-density materials and field of views. Clin. Oral Implants Res. 2017, 28, 1509-1514. [CrossRef]

32. Lupi, S.M.; Galinetto, P.; Cislaghi, M.; Baena, A.R.Y.; Scribante, A.; Baena, R.R.Y. Geometric distortion of panoramic reconstruction in third molar tilting assessments: A comprehensive evaluation. Dentomaxillofac. Radiol. 2018, 47, 20170467. [CrossRef] [PubMed]

33. Special Committee to Revise the Joint AAE/AAOMR Position Statement on use of CBCT in Endodontics. AAE and AAOMR Joint Position Statement: Use of Cone Beam Computed Tomography in endodontics 2015 update. Oral Surg. Oral Med. Oral Pathol. Oral Radiol. 2015, 120, 508-512. [CrossRef] [PubMed]

34. Schulze, R.; Heil, U.; Groß, D.; Bruellmann, D.; Dranischnikow, E.; Schwanecke, U.; Schoemer, E. Artefacts in CBCT: A review. Dentomaxillofac. Radiol. 2011, 40, 265-273. [CrossRef] [PubMed]

35. Pauwels, R.; Stamatakis, H.; Bosmans, H.; Bogaerts, R.; Jacobs, R.; Horner, K.; Tsiklakis, K. Quantification of metal artifacts on cone beam computed tomography images. Clin. Oral Implants Res. 2013, 24, 94-99. [CrossRef] 
36. Iikubo, M.; Nishioka, T.; Okura, S.; Kobayashi, K.; Sano, T.; Katsumata, A.; Ariji, E.; Kojima, I.; Sakamoto, M.; Sasano, T. Influence of voxel size and scan field of view on fracture-like artifacts from gutta-percha obturated endodontically treated teeth on cone-beam computed tomography images. Oral Surg. Oral Med. Oral Pathol. Oral Radiol. 2016, 122, 631-637. [CrossRef]

37. Helvacioglu-Yigit, D.; Kocasarac, H.D.; Bechara, B.; Noujeim, M. Evaluation and reduction of artifacts generated by 4 different root-end filling materials by using multiple cone-beam computed tomography imaging settings. J. Endod. 2016, 42, 307-314. [CrossRef]

38. Celikten, B.; Jacobs, R.; Vasconcelos, K.d.F.; Huang, Y.; Nicolielo, L.F.P.; Orhan, K. Assessment of volumetric distortion artifact in filled root canals using different cone-beam computed tomographic devices. J. Endod. 2017, 43, 1517-1521. [CrossRef]

39. Katsumata, A.; Hirukawa, A.; Noujeim, M.; Okumura, S.; Naitoh, M.; Fujishita, M.; Ariji, E.; Langlais, R.P. Image artifact in dental cone-beam CT. Oral Surg. Oral Med. Oral Pathol. Oral Radiol. Endod. 2006, 101, 652-657. [CrossRef]

40. Suetens, P. Fundamentals of Medical Imaging; Cambridge University Press: Cambridge, UK, 2017.

41. Vanderstuyft, T.; Tarce, M.; Sanaan, B.; Jacobs, R.; Vasconcelos, K.d.F.; Quirynen, M. Inaccuracy of buccal bone thickness estimation on cone-beam CT due to implant blooming: An ex-vivo study. J. Clin. Periodontol. 2019, 46, 1134-1143. [CrossRef]

Publisher's Note: MDPI stays neutral with regard to jurisdictional claims in published maps and institutional affiliations. 